\title{
The Epigenetic Aspect of Gastric Cancer
}

\author{
Xian Wang and Hongchuan Jin \\ Laboratory of Cancer Epigenetics, Biomedical Research Center, Sir Runrun \\ Shaw Hospital, School of Medicine, Zhejiang University, Hangzhou, \\ China
}

\section{Introduction}

Genetic susceptibility seems to play an important role in some gastric cancers. In some rare cases, gastric cancer can be one part of familial cancer syndromes. A well-known example is the family of Napoleon since the Emperor himself as well as his father and his grandfather had gastric cancer. Generally, hereditary factors include germline mutations of E-cadherin, APC, p53 or mismatch repair genes like hMLH1 or hMSH2. Gatekeeper genes like Ecadherin and APC encode signaling proteins important to cellular proliferation and differentiation while protein products from caretaker genes like p53 or mismatch repair genes are important to maintain the integrality and fidelity of the genome. In addition to gene mutations, gene polymorphisms have been shown to be associated with the susceptibility of gastric cancer (El-Omar et al., 2000; Persson et al., 2011). Interestingly, most of these genes are encoding proinflammatory cytokines, strongly indicating the importance of inflammation to the initiation and progression of gastric cancer.

Environment factors play important roles in the pathogenesis of gastric cancer by affecting the inflammation in the stomach. The infection of Helicobacter pylori is apparently one of the primary risk factors of gastric cancer. In 1994, the World Health Organization and the International Agency for Research on Cancer Consensus group classified H. pylori as a type I carcinogen in human beings. Although numerous studies reported the growth promoting effect of $\mathrm{H}$. pylori or its derived proteins in vitro, no direct evidence about the interaction of $\mathrm{H}$. pylori with cancer initiating or stem cells have been presented. In contrast, accumulating reports indicated that the inflammation induced by $\mathrm{H}$. pylori infection is the key to gastric carcinogenesis. Thus, it was believed that H. pylori infection is the initial step in the stepwise process of gastric carcinogenesis starting from chronic gastritis, gastric atrophy, intestinal metaplasia, dysplasia to gastric carcinoma. Consistently, diets rich in fruit and vegetables is protective factors of gastric cancer since vitamin $C$ are helpful to attenuate inflammation while inflammation-promoting factors such as smoking, foods with high salts and nitrite could facilitate the development of gastric cancer by promoting chronic inflammation.

Microenvironments in chronic inflammatory tissues are rich in growth factors and cytokines important to promote the perpetuation of tumor growth by epigenetically reprogramming cancer stem cells. In addition, there are some DNA damage inducing agents such as reactive oxygen and nitrogen species (RONS) that can cause genomic alterations, promoting the accumulation of mutations in proliferating cancer stem cells (Meira et al., 2008). On the other 
hand, cancer cells during their progression can not only circumvent inhibitory signals from immune cells in inflammatory microenvironments but also suppress the anti-tumor immune response, eventually transforming the inflammation microenvironment into tumor permissive microenvironment, the niche for the survival and expansion of cancer stem cells (Wang and Jin, 2010).

Tumor promoting factors in tumor-permissive microenvironments can reprogram epigenetic regulatory network in cancer cells through various signaling pathways that deregulated in both inflammation and carcinogenesis, such as NF-kB pathway and IL6STAT3 pathway (Pikarsky et al., 2004; Yu et al., 2009a). However, epigenetic changes directly controlled by intracellular signaling pathways can immediately reform cellular response to extracellular signals and therefore most likely precede genetic changes that take several cell divisions to be fixed. Similar to genetic changes, epigenetic changes can also affect the activity of many signaling pathways critical to cancer development. By doing so, epigenetic trans-generation of extracellular signals plays important roles in the initiation of many sporadic cancers (Figure 1).

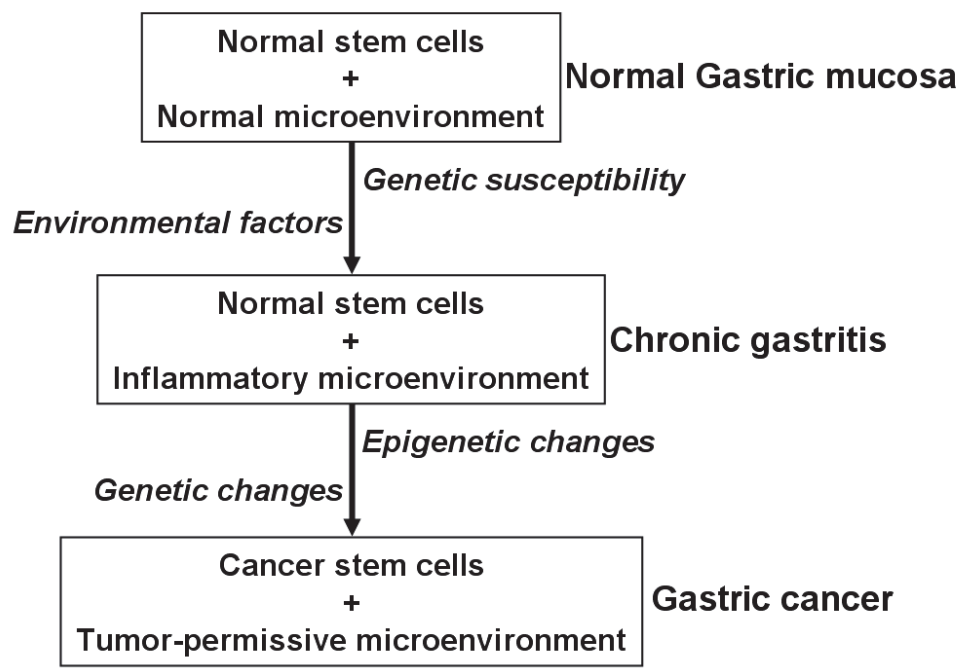

Fig. 1. Gastric cancer is resulting from the accumulation of genetic and epigenetic changes. Genetic factors such as polymorphism of genes encoding cytokines affect the pathogenesis of inflammation induced by environmental factors such as $\mathrm{H}$. Pylori infection. Bioactive factors enriched in inflammatory microenvironments such as IL-6, INF- $\alpha$ and other prosurvival and anti-apoptotic signals could reprogram epigenetic regulatory network to promote genetic changes and the subsequent malignant transformation of stem or progenitor cells. The interaction of transformed stem cells with microenvironment gradually transformed microenvironment into tumor permissive microenvironment and stem cells into cancer stem cells.

\section{Epigenetic view of gastric carcinogenesis}

Epigenetic information is defined as cellular information heritable during cell division in addition to DNA sequence. Epigenetic network regulates the expression or function but not 
the sequence of genes. Up to date, the major components of epigenetic regulatory network include DNA methylation, non-coding RNAs mainly microRNAs and histone modifications. Similar to genetic changes, some of epigenetic changes are important to maintain the malignant phenotypes of cancer cells and thereby could be named as driver epigenetic changes while the others are passenger epigenetic changes since they are passively altered during cancer development.

\begin{tabular}{ccc}
\hline Mechanism & Name & Scale \\
\hline Bisulfite dependent & MS-PCR & Single Gene \\
BGS & Single Gene \\
MDFS & Single Gene \\
Cobra & Single Gene \\
\hline Bisulfite independent & Enzyme digestion-Southern Blot & Single Gene \\
& Enzyme digestion-PCR & Single Gene \\
& RLGS & Genome wide \\
aPRIMES & Genome wide \\
MB-PCR & Single Gene \\
& MB-Array/-sequencing & Genome wide \\
\hline
\end{tabular}

Table 1. Methods to detect DNA methylation

\section{Aberrant DNA methylation in gastric carcinogenesis}

DNA methylation is a type of chemical modification with the covalent addition of a methyl group to the fifth position of cytosine predominantly within the CpG dinucleotides. As one of the major mechanisms of epigenetic regulation, DNA methylation is involved in a number of important biological processes including linage-specific gene expression, parental or maternal imprinting and tumor suppressor gene silencing in carcinogenesis (Bird, 1986; Jones, 2002). Aberrant DNA methylation is deeply involved in gastric carcinogenesis by affecting various cellular processes including signal transduction, cell cycle regulation and gene expression. In addition to driver methylations, there are passenger methylations that could be used as the biomarkers for the detection or monitoring of cancer development and progression instead of the screening or defining of novel tumor suppressor genes. The genes silenced by DNA methylation in gastric cancer have been intensively discussed and thus will not be included here (Choi and $\mathrm{Wu}, 2005$; Tamura, 2006). Instead, the potential application of DNA methylation in the detection of gastric cancer will be overviewed after the brief introduction of general approaches to detect DNA methylation.

\subsection{General approaches to detect DNA methylation}

In general, the approaches to detect DNA methylation could be grouped into two classes: bisulfite-dependent methods and bisulfite-independent methods (Table 1). Methylated DNA could be differentiated from unmethylated DNA by bisulfite DNA modification or restriction enzyme digestion. Bisulfite treatment could change unmethylated cytosine into uracil while left methylated cytosine unchanged. DNAs with different methylation status respond to the digestion of methylation-sensitive restriction enzymes differently, making it possible to detect DNA methylation indirectly by analyzing the products of enzyme digestion. 
After the conversion of unmethylated cytosine into uracil by bisulfite treatment, methylated DNA could be amplified by methylation specific-PCR (MS-PCR) with specifically designed primers (Herman et al., 1996). The advantage of this method includes the fast detection of DNA methylation with high sensitivity and specificity. The main disadvantage is the low level of resolution to determine the methylation of particular CpG sites only in the 3'terminus of primers. The pattern of multiple methylated $\mathrm{CpG}$ sites could be determined by bisulfite genome sequencing in which PCR products with methylation non-selective primers will be directly sequenced or sequenced indirectly after TA cloning. Alternatively, methylation could be quantified by MethyLight in which methylation or unmethylation specific probes were used in PCR amplification (Eads et al., 2000). Other quantitative methods include MS-HRM (Methylation-sensitive high resolution melting) which takes the advantage of the differences in melting of PCR products from methylated and unmethylated DNA while methylation-dependent fragment separation (MDFS) could detect DNA methylation by comparing differential migration times of PCR products in electrophoresis (Boyd et al., 2006; Wojdacz and Dobrovic, 2007). In the method termed Cobra (combined Bisulfite Restriction Analysis), PCR products from bisulfite-treated DNAs will be digested by restriction enzymes like BstUI and the resulting fraction could directly reflect the percentage of methylated and unchanged CpGs at sites that will be cut by the enzymes. It is relatively sensitive and small amount of DNAs from tiny tissues could be used for Cobra analysis (Xiong and Laird, 1997). However, it is semi-quantitative and restricted to analyze CpGs only in special sites of particular restriction enzymes. Overall, the efficiency of bisulfite conversion which is a complicated and time consuming procedure with relatively low sensitivity and high false positive rate is the critical factor for bisulfite dependent approaches to quantify DNA methylation.

In bisulfite independent groups, methylated DNAs are differentiated from unmethylated DNA by either enzyme digestion or affinity enrichment. In contrast to other quantification methods like MSP, enzyme digestion based methods could analyze the methylation pattern of multiple CpGs sites. The resulting products from methylation-sensitive restriction enzymes could be further analyzed by Souther blot or PCR at the single gene level and RLGS (restriction landmark genomic scanning) or aPRIMES (array based profiling of reference independent methylation status) in genome-wide level to screening novel methylated sites. The influence of digestion efficiency could be adjusted by the internal control which could not be cut by the particular enzyme irrespective of DNA methylation. Methylated DNA could also be analyzed by PCR, sequencing or array based hybridization after being enriched by anti-5-methylcytosine antibody or methylation binding domain (MBD) containing proteins. It could yield the information including both the level and pattern of DNA methylation with physiological relevance.

\subsection{DNA methylation as biomarkers for gastric cancer}

Although there are many studies reporting that methylation of particular genes could be useful to predict the prognosis of gastric cancer, few of them were validated to be superior to classical prognosis prediction factors such as TNM staging (Liu et al., 2010; Yu et al., $2009 \mathrm{~b})$. Therefore, the clinical application of DNA methylation in prognosis predication of gastric cancer remains uncertain. In contrast, the detection of methylated DNA markers is believed to be useful to detect newly and relapsed gastric cancer, thus representing a promising approach of developing non-invasive detection for gastric cancer progression (Corvalan and Maturana, 2010; Laird, 2003). 
Biomarker detection in peritoneal fluid is clinically important and feasible to determine the micrometastesis to the peritoneum of gastric cancer which is the most frequent event in recurrent gastric cancer and often associated with resistance to chemotherapy and poor prognosis. The detection of peritoneal micrometastasis is critical for patients to take timely and correct treatment based on an accurate diagnosis. Based on the quantitatively detection of methylated DNAs with the MethyLight method, DNA methylation in peritoneal fluids was found to be able to detect occult neoplastic cells in the peritoneum (Hiraki et al., 2011; Hiraki et al., 2010). Among 11 genes reported to be methylated in gastric cancer, BNIP3, CHFR, CYP1B1, MINT25, SFRP2, and RASSF2 were specifically methylated in tumor tissues but not adjacent non-tumor tissues. Interestingly, the methylation status of all six genes were significantly different among three different groups: patients with tumor invasion under muscularis propria (MP) $(n=42$, methylation percentage: $0-5 \%)$, patients with tumor invasion beyond the MP $(n=45$, methylation percentage: $0-15 \%)$ and patients with histologically or cytologically confirmed peritoneal metastasis $(n=20$, methylation percentage: $15-45 \%$ ). Among 45 patients with tumor invasion beyond the MP, 3 of 9 patients with methylation in any of 6 genes were diagnosed as peritoneal recurrence later while only 1 out of 35 patients without methylation in any of 6 genes developed peritoneal metastasis at least 8 months after surgery (Hiraki et al., 2011). Other potential methylation markers of peritoneal metastasis of gastric cancer include RUNX3 which was silenced by DNA methylation in $100 \%$ of peritoneal metastases of gastric cancers and $75 \%$ of primary gastric cancers but not normal gastric mucosa (Sakakura et al., 2005).

In addition to detect methylated DNA in peritoneal fluids, researchers have endeavored to develop sensitive methods to quantify methylated DNA in peripheral bloods. It is promising to identify sensitive circulating biomarkers to detect early gastric cancer at a curable stage.

In a qualitative analysis of methylated p16, E-cadherin, and retinoic acid receptor-1 (RARbeta) in serum, 52 patients (48\%) of the 109 preoperative gastric cancer patients showed hypermethylation of at least one gene while no methylation of any of three genes was detected in control sera (Ikoma et al., 2007). Furthermore, methylation of three genes was detected in 2 of the 3 patients with recurrence, indicating that the detection of the methylated DNA in circulation could facilitate the early detection of newly and recurrent gastric cancer. The methylations of p16, Reprimo as well as RASSF1A were also proposed as potential biomarkers for early detection of gastric cancer (Abbaszadegan et al., 2008; Bernal et al., 2008; Wang et al., 2008).

The quantitative analysis of RUNX3 methylation in serum revealed that methylated RUNX3 was detected in $29 \%(19 / 65)$ of gastric cancer patients and the serum level of methylated RUNX3 was concordant with tumor burden as well as disease stage, histology, lymphatic and vascular invasion (Sakakura et al., 2009). In addition, it seems to be more sensitive than serum level of carcinoembryonic antigen (CEA) as a biomarker for the detection of gastric cancer. However, the methylation of RUNX3 is not specific to gastric cancer and methylated RUNX3 could be detected in patients with various cancers such as breast cancer and lung cancer, indicating that methylation of RUNX3 could be more useful in monitoring the progression or recurrence of gastric cancer than in screening asymptomatic patients with early gastric cancer (Tan et al., 2007). Similarly, preferential methylation in the serum DNA of gastric cancer patients was noted in APC (17\%), E-cadherin (13\%), hMLH1 (41\%) and TIMP3 (17\%) genes and patients with advanced gastric cancer tended to have higher 
concentrations of methylated APC, TIMP3 and hMLH1 in the serum (Leung et al., 2005). Overall, methylations in at least one of these markers were detected in the serum of 33 patients $(55 \%)$ while no methylation was detected in normal subjects. The combined use of APC and E-cadherin methylation markers identified a subgroup of gastric cancer patients with worse prognosis (Leung et al., 2005).

Similar to diver mutations, methylations in critical or driver genes are most likely not specific to gastric cancer. The value of driver methylation in the screening of gastric cancer is certainly controversial. Most of potential biomarkers, however, are usually transformed from functional studies. Many passenger methylations were, thus, discarded for further validation of their potential as indicators of gastric cancer development. Many biomarkers currently used in clinic, such as AFP, CEA and CA-125, are not functional oncogenes or tumor suppressors per se. To identify biomarkers for clinical application, more attention should be paid to those passenger methylations instead of driver methylations although they are probably not important to the development or progression of gastric cancer in function. In addition, quantitative MSP is currently the most often used approach to detect DNA methylated in blood. It would be more interesting to see the progress on the biomarkers identified by methods based on affinity enrichment since methylation contents with physiological relevance instead of single or few methylated sites could be determined.

\section{MicroRNAs deregulated in gastric carcinogenesis}

Although there are some discrepancies in the microRNA profiling of cell lines and primary tissues, microRNAome as a whole is downregulated in human carcinogenesis. It was believed that the general downregulation of microRNAs in cancer cells is mainly caused by the impaired post-transcriptional maturation of microRNAs starting from primary microRNA transcripts rather than the transcriptional of microRNA genes (Croce, 2009; Lee et al., 2008; Slezak-Prochazka et al., 2010; Thomson et al., 2006; White et al., 2005; Winter et al., 2009). The functions of microprocessors necessary and sufficient for processing microRNA precursors are generally suppressed in cancer cells partially due to the reduced expression of Drosha and Dicer, two major enzymes responsible for the maturation of microRNAs (Dedes et al., 2011; Hwang et al., 2009; Karube et al., 2005; Lee et al., 2008; Lin et al., 2010; Merritt et al., 2008). In addition, proteins with tumor suppressing functions like p53 were found to participate in the maturation of microRNAs (Bikkavilli and Malbon, 2010; Davis et al., 2008; Suzuki et al., 2009).

In contrast to genome-wide downregulation of microRNAs, some microRNAs are specifically upregulated in cancer cells. MicroRNAs have been implicated in the control of many fundamental cellular and physiological processes such as cellular differentiation and proliferation, stem cell maintenance and tissue development. By acting as oncogenes or tumor suppressors, microRNAs also play a significant role in cellular transformation and carcinogenesis (Inui et al., 2010; Wiemer, 2007; Wu et al., 2010). In the next, we will briefly overview the very recent studies on the relevance of microRNAs deregulated in gastric carcinogenesis to signal transduction, cell cycle and apoptosis control, and transcriptional regulation.

\subsection{MicroRNAs in signal transduction}

MiR-204 and probably miR-211 are downregulated in gastric cancer, contributing to the aberrant Ras activation by inhibiting the expression of ezrin (Lam et al., 2011). As a 
membrane-cytoskeleton linker protein, ezrin can promote Ras activation by stimulating the assembly of SOS-Ras complex (Morrison et al., 2007). Therefore, downregulation of miR-204 in gastric cancer represents a new mechanism of aberrant Ras activation which was often attributed to Ras mutations in many other cancers. CDC42, one Ras-related small G protein that plays important roles in the regulation of cell motility and tumor metastasis, was found to be targeted by miR-137 in gastric cancer cells (Chen et al., 2011). MiR-137 was downregulated in many cancers including gastric cancer probably due to the hypermethylation of its promoter. As the upstream regulator of MAPK signaling, EGF receptor ERBB2 was found as the direct target of miR-125a-5p (Nishida et al., 2011). While miR-125a-5p could potently suppress the proliferation of gastric cancer cells, low expression levels of miR-125a-5p were associated with enhanced malignant potential such as tumor size, tumor invasion and liver metastasis. By blocking apoptosis and promoting cell survival, NF-kappaB pathway plays important roles in both inflammation and cancer and is often activated in gastric carcinogenesis. NF-kappaB1 is directly targeted by miR-9 which was downregulated in gastric carcinomas (Wan et al., 2010). MiR-516a-3p can block metastatic dissemination of gastric cancer cells and was downregulated in highly metastatic gastric carcinoma cells. It can suppress the expression of sulfatase 1 which is known to promote the activation of wnt/beta-catenin signaling pathway by removing 6-O-sulfates from heparan sulfate proteoglycans on the cell surface and causing the release of membranebound wnt ligands from plasma membrane (Takei et al., 2011). The G-protein coupled receptor of gastrin, cholecystokinin B receptor (CCKBR), is regulated by miR-148b which was downregulated in gastric cancer (Song et al., 2011). Restored expression of miR-148b in gastric cancer cells inhibited cell growth both in vitro and in vivo.

\subsection{MicroRNAs in cell cycle and apoptosis control}

Cell cycle checkpoints consist of many proteins including cyclins, cyclin dependent kinases (CDKs) and CDK inhibitors (CKIs) to secure the integrity and fidelity of genome during cell mitosis. It was found that members of same family of CKIs could be regulated by microRNAs in one cluster. For example, miR-25 targeted p57 (Kip2) and the other two microRNAs in this cluster suppressed the expression of p21 (Cip1); while miR-222 and miR221 cluster regulated both p27 (Kip1) and p57 (Kim et al., 2009). MicroRNAs in one cluster usually display similar pattern of expression, therefore ensuring the effect to attenuate the function of targeted proteins by interacting with different regions in $3^{\prime}$-UTR of the same gene. Cyclin G1 was targeted by miR-122 which was downregulated in gastric cancer and colorectal cancer probably due to aberrant activation of wnt signaling (Fornari et al., 2009; Wang et al., 2009).

As a direct target of p53, miR-34 was downregulated in gastric cancer. MiR-34 could inhibit the growth of gastric cancer cells by targeting anti-apoptotic oncoprotein Bcl-2 (Ji et al., 2008). Bcl-2 was also targeted by miR-181b, which was downregulated in multidrugresistant human gastric cancer cell line SGC7901/vincristine (VCR). Enforced miR-181b expression reduced Bcl-2 protein level and sensitized SGC7901/VCR to VCR-induced apoptosis (Zhu et al., 2010). The novel tumor suppressor protein programmed cell death 4 (PDCD4) was downregulated in several human solid cancer types. PDCD4 was the target of miR-21 which was upregulated in gastric cancer in response to the activation of NF-kB signaling by smoking and many other factors such as inflammation (Motoyama et al., 2010). 


\subsection{MicroRNAs in transcription regulation}

SRY (sex-determining region Y)-box 2 (SOX2) is a crucial transcription factor for the maintenance of stem cell pluripotency and the determination of cell fate. Its expression was reduced in gastric cancer cells due to the upregulation of miR-126 (Otsubo et al., 2011). Enhanced expression of miR-126 significantly promoted both anchorage-dependent and independent growth of gastric cancer cells by reducing SOX2 expression. Similarly, SOX4 was upregulated in gastric cancers compared with benign gastric tissues probably resulting from the epigenetic silencing of miR-129-2 (Shen et al., 2010). Restoration of miR-129-2 induced apoptosis of gastric cancer cells.

In addition to transcription factors that regulate gene expression through direct interaction with DNA, many other proteins especially in the epigenetic regulatory network are also targeted by microRNAs. As one component in the polycomb complex, EZH2 plays important roles in stem cell homeostasis as well as cancer development. It has been proven to be upregulated in many cancers including gastric cancer. Such an upregulation is at least partially caused by the downregulation of miR-101 (Varambally et al., 2008; Wang et al., 2010). Restoration of miR-101 expression in gastric cancer cells led to the significant inhibition of cellular proliferation, migration and invasion as well as tumorigenicity. Another chromatin remodeling protein ING4 (Inhibitor of growth family, member 4) was targeted by miR-650 which was downregulated in gastric cancer and could promote tumorigenesis and proliferation of gastric cancer cells (Zhang et al., 2010). Methyl-CpGbinding protein $\mathrm{MeCP} 2$ could promote cancer development by initiating the assembly of transcription inhibitory complex to silence the expression of tumor suppressors. It was found to be the direct target of miR-212 which was downregulated in gastric cancer (Wada et al., 2010). Transfection of the miR-212 precursor into gastric cancer cells induced significant decrease of cell growth in vitro. In addition to methylated DNA binding proteins and histone modification related proteins, DNA methyltransferases (DNMTs) were directly targeted by microRNAs as well (Ng et al., 2009b). MiR-143 was frequently downregulated in gastric cancer and many other cancers and one target directly regulated by miR-143 was turned out to be DNA methyltranserase-3A (DNMT-3A) (Takagi et al., 2009). The transcription of DNMT-3A was resulted from aberrant Ras activation. Therefore, downregulation of miR-143 could be in concert with Ras activation to promote carcinogenesis by increasing the expression of DNMTs to promote hypermethylationmediated silencing of tumor suppressors.

\subsection{Deregulated microRNAs as biomarkers for gastric cancer}

The number of microRNAs deregulated in gastric cancer is still increasing (Hou et al., 2011; Lee and Dutta, 2009; Wu et al., 2010). Many other microRNAs important to gastric carcinogenesis were not included due to the limitation of the space. For example, macrophage migration inhibitory factor (MIF) which plays important roles in the transformation of tumor-permissive microenvironment was targeted by miR-451 and miR451 was downregulated in gastric cancer. The downregulation of miR-451 was associated with worse prognosis and restoration of miR-451 expression in gastric cancer cells reduced cell proliferation and increased sensitivity to radiation (Bandres et al., 2009). Microsatellite instability (MSI) was believed to be one important feature of some gastric cancers. MSI was usually caused by the mutations in mismatch repair (MMR) genes or reduced expression of 
MMRs. A microRNA contribution to MSI was recently identified. MiR-155 which was overexpressed in gastric cancers could target the expression of several MMR genes, such as hMSH2, hMSH6, and hMLH1 (Valeri et al., 2010).

The clarification of their biological relevance will certainly deepen our understanding of carcinogenesis so that new and effective therapeutics could be developed. Different microRNAs could regulate gene expression by targeting different sites in the $3^{\prime}$-UTR of the same gene and a single microRNA could target more than one gene. Computational predictions indicate over $50 \%$ of human protein-coding genes might be regulated by microRNAs although there are only several hundred of microRNAs in human genome. In addition, microRNA could regulate gene expression by interacting with 5'-UTR even other elements in the gene, making it challenging to understand the biological relevance of microRNAs.

Interestingly, microRNAs were also recognized as the next generation of biomarkers for the diagnosis and prognosis prediction of cancers due to the development of methods to quantify microRNA expression in both tissues and bloods. Realtime RT-PCR and in situ hybridization could detect the expression of microRNA in tissues quantitatively or semiquantitatively. Many studies have confirmed that microRNAs could be used for prognosis prediction (Iorio et al., 2008). For example, miR-125a-5p expression was found to be an independent prognostic factor and its lower expression in tumor tissues was often associated with shorter survival (Nishida et al., 2011). In a screening with a large cohort of 353 gastric samples, miR-125b, miR-199a and miR-100 were found to be related with the progression of gastric cancer while the downregulation of let-7g and miR-433 and the upregulation of miR-214 were associated with unfavorable outcome in overall survival independent of clinical covariates, including depth of invasion, lymph-node metastasis, and stage (Ueda et al., 2010). Based on the study of a relative small scale cohort of 160 gastric cancer patients, a signature consisting of miR-10b, miR-21, miR-223, miR-338, let-7a, miR$30 a-5 p$ and miR-126 was found as an independent predictor of overall survival and relapsefree survival (Li et al., 2010). Six microRNAs including miR-103, miR-21, miR-145, miR-106b, miR-146a and miR-148a were screened out from a total of 857 microRNA probes to separate node-positive from node-negative gastric cancers, indicating that these six miRNAs may be useful for the decision-making of doctors by the prediction of potential lymph node metastasis (Tchernitsa et al., 2010). Other microRNAs such as miR-27a was also related with the lymph node metastasis of gastric cancer (Katada et al., 2009). However, no microRNA signature was commonly accepted to predict the prognosis of gastric cancer since results from different labs were usually different. This could be due to the different methods used in different labs. Alternatively, the ethnic variation could be one of the reasons. Large scale multi-centered clinical trials will be warranted to validate the relevance of microRNA based signature to the prognosis predication of gastric cancer.

Given the stability in nature, microRNAs in peripheral blood or other body fluids were recognized as the ideal biomarkers for various cancers $(\mathrm{Ng}$ et al., 2009a). The plasma miRNA levels usually reflected the expression level of microRNAs in tumor tissues (Tsujiura et al., 2010). Microarray and new generations of sequencing platforms have been widely used to screen circulating microRNAs for the diagnosis of gastric cancer. Solexa sequencing of microRNAs in serum from 20 patients with gastric cancer and 20 age- and gender-matched tumour-free controls revealed 19 miRNAs specifically upregulated in gastric cancer. Five of them including miR-1, miR-20a, miR-27a, miR-34 and miR-423-5p were confirmed by qRT-PCR analysis. In a validation set consisting of 142 serum samples from gastric cancer patients and 105 control serum samples, the quantification of serum 
level of these five microRNAs could successfully separate gastric cancer cases from normal donors. The areas under the receiver operating characteristic (ROC) curve of this fivemicroRNA signature was even markedly higher than these of widely used biomarkers such as serum carcinoembryonic antigen (CEA) and carbohydrate antigen 19-9 (CA19-9), indicating that expression levels of this serum miRNA-based biomarker could be potential biomarkers for the detection of gastric cancer (Liu et al., 2011). Other reports indicated that plasma level of miR-17, miR-106b, and miR-106a could also be useful for the detection of gastric cancer (Tsujiura et al., 2010; Zhou et al., 2010). Currently, the detection of circulating microRNAs has received a great deal of attention for its potential application for the early detection and postoperative recurrence prediction of gastric cancer. Although approaches based on the detection of circulating nucleic acid have been approved for the clinical application, microRNAs based methods are still in their infancy. The stability of microRNAs and the sensitivity of microRNA detection certainly make microRNAs promising biomarkers for cancer detection or monitoring. More clinical trials will be needed to confirm the values of microRNA biomarkers in screening high-risk individuals for early detection of gastric cancer by further invasive examinations such as gastroendoscopy.

\section{Conclusions and perspectives}

In recent years, it has become apparent that gastric cancer is resulting from the accumulation of both genetic and epigenetic changes. Chronic inflammation gradually renders inflammatory microenvironment into tumor permissive, allowing the survival and growth of cancer initiating cells with reprogrammed epigenetic regulatory network. As the major components of epigenetic regulatory network, DNA methylation and microRNA are deregulated in cancer initiating cells. Although the mechanisms underlying aberrant DNA methylation as well as dysregulated microRNA expression are largely unknown, changes in patterns of DNA methylation and microRNA expression are believed to contribute to the initiation and progression of gastric cancer by altering the expression of genes important to control apoptosis, cellular proliferation and differentiation. Approaches to renormalize methylation patterns in both global levels such as DNA methyltransferases inhibitors or histone deacetyltransferases inhibitors (HDACi) or targeted therapeutics have been developed as novel strategies to treat cancer. Despite its promising future in cancer prevention and intervention, the great promise of cancer epigenetics currently lies in the potential in diagnostics in which epigenetic biomarkers would be helpful for risk assessment, early detection, prognosis prediction and monitoring of treatment response as well as disease relapse. The quantification of DNA methylation and microRNAs in peripheral blood has received a great deal of attention recently. With the progress in the technology of genome-wide analysis such as new generation of sequencing, more and more epigenetic biomarkers specific to gastric cancer will be identified in the peripheral blood, allowing the development of epigenetic biomarker panel alone or in combination with other biochemical biomarkers for the detection and monitoring of gastric cancer.

\section{References}

Abbaszadegan, M.R., Moaven, O., Sima, H.R., Ghafarzadegan, K., A'Rabi, A., Forghani, M.N., Raziee, H.R., Mashhadinejad, A., Jafarzadeh, M., Esmaili-Shandiz, E., et al. (2008). p16 promoter hypermethylation: a useful serum marker for early detection of gastric cancer. World J Gastroenterol 14, 2055-2060. 
Bandres, E., Bitarte, N., Arias, F., Agorreta, J., Fortes, P., Agirre, X., Zarate, R., DiazGonzalez, J.A., Ramirez, N., Sola, J.J., et al. (2009). microRNA-451 regulates macrophage migration inhibitory factor production and proliferation of gastrointestinal cancer cells. Clin Cancer Res 15, 2281-2290.

Bernal, C., Aguayo, F., Villarroel, C., Vargas, M., Diaz, I., Ossandon, F.J., Santibanez, E., Palma, M., Aravena, E., Barrientos, C., et al. (2008). Reprimo as a potential biomarker for early detection in gastric cancer. Clin Cancer Res 14, 6264-6269.

Bikkavilli, R.K., and Malbon, C.C. (2010). Dishevelled-KSRP complex regulates Wnt signaling through post-transcriptional stabilization of beta-catenin mRNA. J Cell Sci 123, 1352-1362.

Bird, A.P. (1986). CpG-rich islands and the function of DNA methylation. Nature 321, 209213.

Boyd, V.L., Moody, K.I., Karger, A.E., Livak, K.J., Zon, G., and Burns, J.W. (2006). Methylation-dependent fragment separation: direct detection of DNA methylation by capillary electrophoresis of PCR products from bisulfite-converted genomic DNA. Anal Biochem 354, 266-273.

Chen, Q., Chen, X., Zhang, M., Fan, Q., Luo, S., and Cao, X. (2011). miR-137 Is Frequently Down-Regulated in Gastric Cancer and Is a Negative Regulator of Cdc42. Dig Dis Sci.

Choi, I.S., and Wu, T.T. (2005). Epigenetic alterations in gastric carcinogenesis. Cell Res 15, 247-254.

Corvalan, A.H., and Maturana, M.J. (2010). Recent patents of DNA methylation biomarkers in gastrointestinal oncology. Recent Pat DNA Gene Seq 4, 202-209.

Croce, C.M. (2009). Causes and consequences of microRNA dysregulation in cancer. Nat Rev Genet 10, 704-714.

Davis, B.N., Hilyard, A.C., Lagna, G., and Hata, A. (2008). SMAD proteins control DROSHA-mediated microRNA maturation. Nature 454, 56-61.

Dedes, K.J., Natrajan, R., Lambros, M.B., Geyer, F.C., Lopez-Garcia, M.A., Savage, K., Jones, R.L., and Reis-Filho, J.S. (2011). Down-regulation of the miRNA master regulators Drosha and Dicer is associated with specific subgroups of breast cancer. Eur J Cancer 47, 138-150.

Eads, C.A., Danenberg, K.D., Kawakami, K., Saltz, L.B., Blake, C., Shibata, D., Danenberg, P.V., and Laird, P.W. (2000). MethyLight: a high-throughput assay to measure DNA methylation. Nucleic Acids Res 28, E32.

El-Omar, E.M., Carrington, M., Chow, W.H., McColl, K.E., Bream, J.H., Young, H.A., Herrera, J., Lissowska, J., Yuan, C.C., Rothman, N., et al. (2000). Interleukin-1 polymorphisms associated with increased risk of gastric cancer. Nature 404, 398402.

Fornari, F., Gramantieri, L., Giovannini, C., Veronese, A., Ferracin, M., Sabbioni, S., Calin, G.A., Grazi, G.L., Croce, C.M., Tavolari, S., et al. (2009). MiR-122/cyclin G1 interaction modulates p53 activity and affects doxorubicin sensitivity of human hepatocarcinoma cells. Cancer Res 69, 5761-5767.

Herman, J.G., Graff, J.R., Myohanen, S., Nelkin, B.D., and Baylin, S.B. (1996). Methylationspecific PCR: a novel PCR assay for methylation status of CpG islands. Proc Natl Acad Sci U S A 93, 9821-9826. 
Hiraki, M., Kitajima, Y., Koga, Y., Tanaka, T., Nakamura, J., Hashiguchi, K., Noshiro, H., and Miyazaki, K. (2011). Aberrant Gene Methylation Is a Biomarker for the Detection of Cancer Cells in Peritoneal Wash Samples from Advanced Gastric Cancer Patients. Ann Surg Oncol.

Hiraki, M., Kitajima, Y., Sato, S., Nakamura, J., Hashiguchi, K., Noshiro, H., and Miyazaki, K. (2010). Aberrant gene methylation in the peritoneal fluid is a risk factor predicting peritoneal recurrence in gastric cancer. World J Gastroenterol 16, 330338.

Hou, Z., Xie, L., Yu, L., Qian, X., and Liu, B. (2011). MicroRNA-146a is down-regulated in gastric cancer and regulates cell proliferation and apoptosis. Med Oncol.

Hwang, H.W., Wentzel, E.A., and Mendell, J.T. (2009). Cell-cell contact globally activates microRNA biogenesis. Proc Natl Acad Sci U S A 106, 7016-7021.

Ikoma, H., Ichikawa, D., Daito, I., Nobuyuki, T., Koike, H., Okamoto, K., Ochiai, T., Ueda, Y., Yamagishi, H., and Otsuji, E. (2007). Clinical application of methylation specificpolymerase chain reaction in serum of patients with gastric cancer. Hepatogastroenterology 54, 946-950.

Inui, M., Martello, G., and Piccolo, S. (2010). MicroRNA control of signal transduction. Nat Rev Mol Cell Biol 11, 252-263.

Iorio, M.V., Casalini, P., Tagliabue, E., Menard, S., and Croce, C.M. (2008). MicroRNA profiling as a tool to understand prognosis, therapy response and resistance in breast cancer. Eur J Cancer 44, 2753-2759.

Ji, Q., Hao, X., Meng, Y., Zhang, M., Desano, J., Fan, D., and Xu, L. (2008). Restoration of tumor suppressor miR-34 inhibits human p53-mutant gastric cancer tumorspheres. BMC Cancer 8, 266.

Jones, P.A. (2002). DNA methylation and cancer. Oncogene 21, 5358-5360.

Karube, Y., Tanaka, H., Osada, H., Tomida, S., Tatematsu, Y., Yanagisawa, K., Yatabe, Y., Takamizawa, J., Miyoshi, S., Mitsudomi, T., et al. (2005). Reduced expression of Dicer associated with poor prognosis in lung cancer patients. Cancer Sci 96, 111115.

Katada, T., Ishiguro, H., Kuwabara, Y., Kimura, M., Mitui, A., Mori, Y., Ogawa, R., Harata, K., and Fujii, Y. (2009). microRNA expression profile in undifferentiated gastric cancer. Int J Oncol 34, 537-542.

Kim, Y.K., Yu, J., Han, T.S., Park, S.Y., Namkoong, B., Kim, D.H., Hur, K., Yoo, M.W., Lee, H.J., Yang, H.K., et al. (2009). Functional links between clustered microRNAs: suppression of cell-cycle inhibitors by microRNA clusters in gastric cancer. Nucleic Acids Res 37, 1672-1681.

Laird, P.W. (2003). The power and the promise of DNA methylation markers. Nat Rev Cancer 3, 253-266.

Lam, E.K., Wang, X., Shin, V.Y., Zhang, S., Morrison, H., Sun, J., Ng, E.K., Yu, J., and Jin, H. (2011). A microRNA contribution to aberrant Ras activation in gastric cancer. Am J Transl Res 3, 209-218.

Lee, E.J., Baek, M., Gusev, Y., Brackett, D.J., Nuovo, G.J., and Schmittgen, T.D. (2008). Systematic evaluation of microRNA processing patterns in tissues, cell lines, and tumors. RNA 14, 35-42.

Lee, Y.S., and Dutta, A. (2009). MicroRNAs in cancer. Annu Rev Pathol 4, 199-227. 
Leung, W.K., To, K.F., Chu, E.S., Chan, M.W., Bai, A.H., Ng, E.K., Chan, F.K., and Sung, J.J. (2005). Potential diagnostic and prognostic values of detecting promoter hypermethylation in the serum of patients with gastric cancer. Br J Cancer 92, 21902194.

Li, X., Zhang, Y., Ding, J., Wu, K., and Fan, D. (2010). Survival prediction of gastric cancer by a seven-microRNA signature. Gut 59, 579-585.

Lin, R.J., Lin, Y.C., Chen, J., Kuo, H.H., Chen, Y.Y., Diccianni, M.B., London, W.B., Chang, C.H., and $\mathrm{Yu}$, A.L. (2010). microRNA signature and expression of Dicer and Drosha can predict prognosis and delineate risk groups in neuroblastoma. Cancer Res 70, 7841-7850.

Liu, R., Zhang, C., Hu, Z., Li, G., Wang, C., Yang, C., Huang, D., Chen, X., Zhang, H., Zhuang, R., et al. (2011). A five-microRNA signature identified from genome-wide serum microRNA expression profiling serves as a fingerprint for gastric cancer diagnosis. Eur J Cancer 47, 784-791.

Liu, X., Wang, X., Zhang, J., Lam, E.K., Shin, V.Y., Cheng, A.S., Yu, J., Chan, F.K., Sung, J.J., and Jin, H.C. (2010). Warburg effect revisited: an epigenetic link between glycolysis and gastric carcinogenesis. Oncogene 29, 442-450.

Meira, L.B., Bugni, J.M., Green, S.L., Lee, C.W., Pang, B., Borenshtein, D., Rickman, B.H., Rogers, A.B., Moroski-Erkul, C.A., McFaline, J.L., et al. (2008). DNA damage induced by chronic inflammation contributes to colon carcinogenesis in mice. J Clin Invest 118, 2516-2525.

Merritt, W.M., Lin, Y.G., Han, L.Y., Kamat, A.A., Spannuth, W.A., Schmandt, R., Urbauer, D., Pennacchio, L.A., Cheng, J.F., Nick, A.M., et al. (2008). Dicer, Drosha, and outcomes in patients with ovarian cancer. N Engl J Med 359, 2641-2650.

Morrison, H., Sperka, T., Manent, J., Giovannini, M., Ponta, H., and Herrlich, P. (2007). Merlin/neurofibromatosis type 2 suppresses growth by inhibiting the activation of Ras and Rac. Cancer Res 67, 520-527.

Motoyama, K., Inoue, H., Mimori, K., Tanaka, F., Kojima, K., Uetake, H., Sugihara, K., and Mori, M. (2010). Clinicopathological and prognostic significance of PDCD4 and microRNA-21 in human gastric cancer. Int J Oncol 36, 1089-1095.

Ng, E.K., Chong, W.W., Jin, H., Lam, E.K., Shin, V.Y., Yu, J., Poon, T.C., Ng, S.S., and Sung, J.J. (2009a). Differential expression of microRNAs in plasma of patients with colorectal cancer: a potential marker for colorectal cancer screening. Gut 58, 13751381.

Ng, E.K., Tsang, W.P., Ng, S.S., Jin, H.C., Yu, J., Li, J.J., Rocken, C., Ebert, M.P., Kwok, T.T., and Sung, J.J. (2009b). MicroRNA-143 targets DNA methyltransferases 3A in colorectal cancer. Br J Cancer 101, 699-706.

Nishida, N., Mimori, K., Fabbri, M., Yokobori, T., Sudo, T., Tanaka, F., Shibata, K., Ishii, H., Doki, Y., and Mori, M. (2011). MicroRNA-125a-5p is an independent prognostic factor in gastric cancer,and inhibits the proliferation of human gastric cancer cells in combination with trastuzumab. Clin Cancer Res.

Otsubo, T., Akiyama, Y., Hashimoto, Y., Shimada, S., Goto, K., and Yuasa, Y. (2011). MicroRNA-126 inhibits SOX2 expression and contributes to gastric carcinogenesis. PLoS One 6, e16617.

Persson, C., Canedo, P., Machado, J.C., El-Omar, E.M., and Forman, D. (2011). Polymorphisms in inflammatory response genes and their association with gastric 
cancer: A HuGE systematic review and meta-analyses. Am J Epidemiol 173, 259270.

Pikarsky, E., Porat, R.M., Stein, I., Abramovitch, R., Amit, S., Kasem, S., Gutkovich-Pyest, E., Urieli-Shoval, S., Galun, E., and Ben-Neriah, Y. (2004). NF-kappaB functions as a tumour promoter in inflammation-associated cancer. Nature 431, 461-466.

Sakakura, C., Hamada, T., Miyagawa, K., Nishio, M., Miyashita, A., Nagata, H., Ida, H., Yazumi, S., Otsuji, E., Chiba, T., et al. (2009). Quantitative analysis of tumor-derived methylated RUNX3 sequences in the serum of gastric cancer patients. Anticancer Res 29, 2619-2625.

Sakakura, C., Hasegawa, K., Miyagawa, K., Nakashima, S., Yoshikawa, T., Kin, S., Nakase, Y., Yazumi, S., Yamagishi, H., Okanoue, T., et al. (2005). Possible involvement of RUNX3 silencing in the peritoneal metastases of gastric cancers. Clin Cancer Res 11, 6479-6488.

Shen, R., Pan, S., Qi, S., Lin, X., and Cheng, S. (2010). Epigenetic repression of microRNA129-2 leads to overexpression of SOX4 in gastric cancer. Biochem Biophys Res Commun 394, 1047-1052.

Slezak-Prochazka, I., Durmus, S., Kroesen, B.J., and van den Berg, A. (2010). MicroRNAs, macrocontrol: regulation of miRNA processing. RNA 16, 1087-1095.

Song, Y.X., Yue, Z.Y., Wang, Z.N., Xu, Y.Y., Luo, Y., Xu, H.M., Zhang, X., Jiang, L., Xing, C.Z., and Zhang, Y. (2011). MicroRNA-148b is frequently down-regulated in gastric cancer and acts as a tumor suppressor by inhibiting cell proliferation. Mol Cancer $10,1$.

Suzuki, H.I., Yamagata, K., Sugimoto, K., Iwamoto, T., Kato, S., and Miyazono, K. (2009). Modulation of microRNA processing by p53. Nature 460, 529-533.

Takagi, T., Iio, A., Nakagawa, Y., Naoe, T., Tanigawa, N., and Akao, Y. (2009). Decreased expression of microRNA-143 and -145 in human gastric cancers. Oncology 77, $12-$ 21.

Takei, Y., Takigahira, M., Mihara, K., Tarumi, Y., and Yanagihara, K. (2011). The MetastasisAssociated microRNA miR-516a-3p Is a Novel Therapeutic Target for Inhibiting Peritoneal Dissemination of Human Scirrhous Gastric Cancer. Cancer Res 71, 14421453.

Tamura, G. (2006). Alterations of tumor suppressor and tumor-related genes in the development and progression of gastric cancer. World J Gastroenterol 12, 192-198.

Tan, S.H., Ida, H., Lau, Q.C., Goh, B.C., Chieng, W.S., Loh, M., and Ito, Y. (2007). Detection of promoter hypermethylation in serum samples of cancer patients by methylationspecific polymerase chain reaction for tumour suppressor genes including RUNX3. Oncol Rep 18, 1225-1230.

Tchernitsa, O., Kasajima, A., Schafer, R., Kuban, R.J., Ungethum, U., Gyorffy, B., Neumann, U., Simon, E., Weichert, W., Ebert, M.P., et al. (2010). Systematic evaluation of the miRNA-ome and its downstream effects on mRNA expression identifies gastric cancer progression. J Pathol 222, 310-319.

Thomson, J.M., Newman, M., Parker, J.S., Morin-Kensicki, E.M., Wright, T., and Hammond, S.M. (2006). Extensive post-transcriptional regulation of microRNAs and its implications for cancer. Genes Dev 20, 2202-2207. 
Tsujiura, M., Ichikawa, D., Komatsu, S., Shiozaki, A., Takeshita, H., Kosuga, T., Konishi, H., Morimura, R., Deguchi, K., Fujiwara, H., et al. (2010). Circulating microRNAs in plasma of patients with gastric cancers. Br J Cancer 102, 1174-1179.

Ueda, T., Volinia, S., Okumura, H., Shimizu, M., Taccioli, C., Rossi, S., Alder, H., Liu, C.G., Oue, N., Yasui, W., et al. (2010). Relation between microRNA expression and progression and prognosis of gastric cancer: a microRNA expression analysis. Lancet Oncol 11, 136-146.

Ushijima, T., and Sasako, M. (2004). Focus on gastric cancer. Cancer Cell 5, 121-125.

Valeri, N., Gasparini, P., Fabbri, M., Braconi, C., Veronese, A., Lovat, F., Adair, B., Vannini, I., Fanini, F., Bottoni, A., et al. (2010). Modulation of mismatch repair and genomic stability by miR-155. Proc Natl Acad Sci U S A 107, 6982-6987.

Varambally, S., Cao, Q., Mani, R.S., Shankar, S., Wang, X., Ateeq, B., Laxman, B., Cao, X., Jing, X., Ramnarayanan, K., et al. (2008). Genomic loss of microRNA-101 leads to overexpression of histone methyltransferase EZH2 in cancer. Science 322, 16951699.

Wada, R., Akiyama, Y., Hashimoto, Y., Fukamachi, H., and Yuasa, Y. (2010). miR-212 is downregulated and suppresses methyl-CpG-binding protein MeCP2 in human gastric cancer. Int J Cancer 127, 1106-1114.

Wan, H.Y., Guo, L.M., Liu, T., Liu, M., Li, X., and Tang, H. (2010). Regulation of the transcription factor NF-kappaB1 by microRNA-9 in human gastric adenocarcinoma. Mol Cancer 9, 16.

Wang, H.J., Ruan, H.J., He, X.J., Ma, Y.Y., Jiang, X.T., Xia, Y.J., Ye, Z.Y., and Tao, H.Q. (2010). MicroRNA-101 is down-regulated in gastric cancer and involved in cell migration and invasion. Eur J Cancer.

Wang, X., and Jin, H. (2010). The epigenetic basis of Warburg effect. Epigenetics 5.

Wang, X., Lam, E.K., Zhang, J., Jin, H., and Sung, J.J. (2009). MicroRNA-122a functions as a novel tumor suppressor downstream of adenomatous polyposis coli in gastrointestinal cancers. Biochem Biophys Res Commun 387, 376-380.

Wang, Y.C., Yu, Z.H., Liu, C., Xu, L.Z., Yu, W., Lu, J., Zhu, R.M., Li, G.L., Xia, X.Y., Wei, X.W., et al. (2008). Detection of RASSF1A promoter hypermethylation in serum from gastric and colorectal adenocarcinoma patients. World J Gastroenterol 14, 3074-3080.

White, P.S., Thompson, P.M., Gotoh, T., Okawa, E.R., Igarashi, J., Kok, M., Winter, C., Gregory, S.G., Hogarty, M.D., Maris, J.M., et al. (2005). Definition and characterization of a region of 1 p36.3 consistently deleted in neuroblastoma. Oncogene 24, 2684-2694.

Wiemer, E.A. (2007). The role of microRNAs in cancer: no small matter. Eur J Cancer 43, 1529-1544.

Winter, J., Jung, S., Keller, S., Gregory, R.I., and Diederichs, S. (2009). Many roads to maturity: microRNA biogenesis pathways and their regulation. Nat Cell Biol 11, 228-234.

Wojdacz, T.K., and Dobrovic, A. (2007). Methylation-sensitive high resolution melting (MSHRM): a new approach for sensitive and high-throughput assessment of methylation. Nucleic Acids Res 35, e41. 
Wu, W.K., Lee, C.W., Cho, C.H., Fan, D., Wu, K., Yu, J., and Sung, J.J. (2010). MicroRNA dysregulation in gastric cancer: a new player enters the game. Oncogene 29, 57615771.

Xiong, Z., and Laird, P.W. (1997). COBRA: a sensitive and quantitative DNA methylation assay. Nucleic Acids Res 25, 2532-2534.

Yu, H., Pardoll, D., and Jove, R. (2009a). STATs in cancer inflammation and immunity: a leading role for STAT3. Nat Rev Cancer 9, 798-809.

Yu, J., Cheng, Y.Y., Tao, Q., Cheung, K.F., Lam, C.N., Geng, H., Tian, L.W., Wong, Y.P., Tong, J.H., Ying, J.M., et al. (2009b). Methylation of protocadherin 10, a novel tumor suppressor, is associated with poor prognosis in patients with gastric cancer. Gastroenterology 136, 640-651 e641.

Zhang, X., Zhu, W., Zhang, J., Huo, S., Zhou, L., Gu, Z., and Zhang, M. (2010). MicroRNA650 targets ING4 to promote gastric cancer tumorigenicity. Biochem Biophys Res Commun 395, 275-280.

Zhou, H., Guo, J.M., Lou, Y.R., Zhang, X.J., Zhong, F.D., Jiang, Z., Cheng, J., and Xiao, B.X. (2010). Detection of circulating tumor cells in peripheral blood from patients with gastric cancer using microRNA as a marker. J Mol Med 88, 709-717.

Zhu, W., Shan, X., Wang, T., Shu, Y., and Liu, P. (2010). miR-181b modulates multidrug resistance by targeting BCL2 in human cancer cell lines. Int J Cancer 127, 2520-2529. 


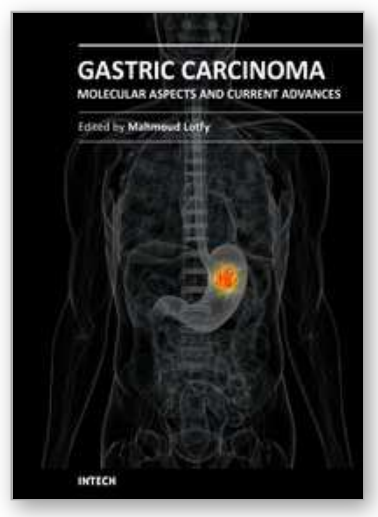

\section{Gastric Carcinoma - Molecular Aspects and Current Advances}

Edited by Prof. Mahmoud Lotfy

ISBN 978-953-307-412-2

Hard cover, 354 pages

Publisher InTech

Published online 15, June, 2011

Published in print edition June, 2011

Gastric cancer is one of the most common tumors worldwide. It has a heterogeneous milieu, where the genetic background, tumor immunology, oxidative stress, and microbial infections are key players in the multiple stages of tumorigenesis. These diverse factors are linked to the prognosis of the gastric cancer and the survival of gastric cancer patients. This book is appropriate for scientists and students in the field of oncology, gastroenterology, molecular biology, immunology, cell biology, biology, biochemistry, and pathology. This authoritative text carefully explains the fundamentals, providing a general overview of the principles followed by more detailed explanations of these recent topics efficiently. The topics presented herein contain the most recent knowledge in gastric cancer concerning the oncogenic signaling, genetic instability, the epigenetic aspect, molecular features and their clinical implications, miRNAs, integrin and E-cadherin, carbohydrateassociated-transferases, free radicals, immune cell responses, mucins, Helicobacter-pylori, neoadjuvant and adjuvant therapy, prophylactic strategy for peritoneal recurrence, and hepatic metastasis.

\section{How to reference}

In order to correctly reference this scholarly work, feel free to copy and paste the following:

Hongchuan Jin and Xian Wang (2011). The Epigenetic Aspects of Gastric Cancer, Gastric Carcinoma Molecular Aspects and Current Advances, Prof. Mahmoud Lotfy (Ed.), ISBN: 978-953-307-412-2, InTech, Available from: http://www.intechopen.com/books/gastric-carcinoma-molecular-aspects-and-currentadvances/the-epigenetic-aspects-of-gastric-cancer

\section{INTECH}

open science | open minds

\section{InTech Europe}

University Campus STeP Ri

Slavka Krautzeka 83/A

51000 Rijeka, Croatia

Phone: +385 (51) 770447

Fax: +385 (51) 686166

www.intechopen.com

\section{InTech China}

Unit 405, Office Block, Hotel Equatorial Shanghai

No.65, Yan An Road (West), Shanghai, 200040, China

中国上海市延安西路65号上海国际贵都大饭店办公楼 405 单元

Phone: +86-21-62489820

Fax: $+86-21-62489821$ 
(C) 2011 The Author(s). Licensee IntechOpen. This chapter is distributed under the terms of the Creative Commons Attribution-NonCommercialShareAlike-3.0 License, which permits use, distribution and reproduction for non-commercial purposes, provided the original is properly cited and derivative works building on this content are distributed under the same license. 